\title{
Management education from episteme to phronesis: The contribution of French didactic theory
}

\author{
Corinne Hahn \\ ESCP Europe \\ Christophe Vignon \\ University of Rennes 1, France
}

\begin{abstract}
In this article, we review some of the criticisms levelled at current management education provided by business schools and the recommendations made by critical management studies scholars. These authors generally recommend placing greater emphasis on phronesis, that is, the manager's practical wisdom. We investigated this path and formulated a practical solution, rooted in the operational framework provided by French didactic theory. It takes the form of a specific pedagogical device, the aim of which is to foster closer connections between experience acquired in professional settings and theoretical knowledge derived from management sciences. We describe our theoretical framework and explain its potential contributions to management education, and then we present the implementing steps of our device. We illustrate these steps through the main elements of a process carried out by a group of students in a European business school. We present some of the observations we made over a 3-year period experimenting with this device. We conclude by outlining the axes that we consider essential in designing this type of device.
\end{abstract}

\section{Keywords \\ Critical reflection, episteme, French didactic theory, management education, phronesis}

\section{Introduction}

The late 20th century saw a rising tide of criticism directed at management education provided by business schools (Burgoyne and Reynolds, 1997; French and Grey, 1996; Mintzberg, 2004). These criticisms were primarily founded on the contention that there was little connection between the content of management courses and the practical realities of management. Building upon these criticisms, further studies have invoked the Aristotelian concept of phronesis to accentuate the importance of practical wisdom in management (Antonacopoulou, 2010; Chia and Holt, 2008; Nonaka et al., 2014; Raelin, 2007; Ramsey, 2014; Shotter and Tsoukas, 2014a, 2014b; Statler, 2014). Over the past few years, we have endeavoured to explore the impact of an alternative teaching method. This method involves the design of pedagogical devices conducive to the development of managerial skills, by intertwining the practical experience acquired in professional settings and the teaching provided by business schools. These devices are based on a framework that has been developed at the intersection of our respective areas of research, rooted in different disciplinary fields - mathematics and education sciences on one hand, and organisation studies on the other.

The article is structured as follows. We begin with a review of the literature that has criticised the current state of management education in business schools. We discuss recent developments under the influence of current thinking on phronesis, understood as an essential form of intelligence in managers. We then examine the framework provided by French didactic theory (FDT) (Brousseau, 1986; Pastré et al., 2006), rooted in the theory of conceptualisation in action (Vergnaud, 1990), sketching the contours of this theory as well as its potential benefits for management education. We continue by outlining the 
original device which we have developed and tested on several groups of students enrolled at a European business school. We illustrate the entire process by presenting the production of one group of students. We present the main observations we made during our 3-year period of experimentation with this device. We conclude by outlining the key axes that we consider essential in designing this type of device.

Business school teaching and its critics

For years now, teaching rationales of business schools have been the target of much criticism; for some observers, they do not sufficiently reflect the realities of management, they disseminate simplistic theories (Moss-Kanter, 2005) and back up their ideological discourse with scientific arguments in order to curry favour with their institutional and commercial partners, students and their parents, and also the accreditation and assessment bodies as well as the media who draw up and publish university rankings (Pfeffer, 2005). The debate surrounding the paradigm shift in the field of management (Clarke and Clegg, 2000) has called into question the actual content of management courses, including the socalled calculating opportunism of individuals (Ghoshal, 2005), an assumption which underlies the extensive use of quantitative technical and managerial techniques in teaching (Hawawini, 2005).

Pedagogical devices are also criticised (Kilkauer, 2011). The tendency towards objectivisation tends to conflate training and education (Thomas and Anthony, 1996). Managers are mostly provided with training rather than a genuine, rounded education. Building on Whitehead's work, Chia (2009) explicitly sets out the difference between these two approaches: "This is the crucial difference between "training" and "education": the former deals with content expertise and the latter with the cultivation of an individual's overall attitude, "style," and disposition' (p. 37).

The disconnect between theories taught and the practical experiences of managers is one of the major weaknesses of the traditional education provided by business schools (Raelin, 2007). This is because the managerial knowledge taught in business schools is based on a priori constructions with no grounding in practical experience. The result is that young managers are provided with ideas too simple to embrace the full complexity of the problems they will encounter.

In this view, management education causes students to adopt certain stances which prevent them from appreciating the diversity of the people with whom they will be expected to work, and they thus acquire cognitive reflexes which are ill-suited to the demands of their professional lives (De Geuser and Fiol, 2003). Students are taught to think in a manner which is reductive, overly technical and blind to the long term (Mintzberg, 2004; Nodoushani and Nodoushani, 1996). Those who argue in favour of overhauling management education stress that business schools are largely responsible for the dehumanisation of current programmes (Petriglieri and Petriglieri, 2015). In their view, this lack of humanity can be largely attributed to the way in which functionalist theories treat intellectual content as totally separate from the actual lived experience of students and managers in the field (Pérezts et al., 2015).

Laufer (1994) proposes that management can be broken down into two dimensions: an existential dimension, defined by the lived experience of managers, and a technical dimension. In this way, management can be seen as a praxeological discipline which lies somewhere between the arts and the sciences (Hahn et al., 2008). Antonacopoulou (2010) thus notes that in MBA programmes, participants are disoriented when faced with knowledge unconnected to life in the field and skills which seem to bear little relation to the complexity of managerial experience. Management education should aim to nurture the lived experience of managers and technical dimensions concomitantly (Mintzberg and Gosling, 2002). Yet graduates are ill-equipped to deal with the realities of the working world (Mintzberg, 2004).

Although business schools do not appear to have taken on board the full implications of these criticisms (Knights, 2015), an alternative to 'mainstream' management education has been gradually developing since the 1970s under the banner of critical management education (CME) (Burgoyne, 1973; EasterbySmith, 1986). CME holds that the knowledge dispensed in traditional management education is not relevant (Dehler et al., 2001). 
For $\mathrm{CME}$, it is an essential priority to imbue management learning with greater meaning for students, enabling them to make an active contribution to this creation of meaning by drawing partly on their own experience, rather than treating them simply as passive consumers of information (Grey, 2004; Grey and Mitev, 1995; Willmott, 1994). Knowing-in-action (Raelin, 2007; Ramsey, 2014) is better suited to retaining deliberate attention than universal abstract theories. For Ramsey (2014), attention is the key cognitive activity, the catalyst required to connect ideas, practices and context. Knowing-in-action focuses more on practical implementation than on abstract theories, since within this logic, interaction with the outside world should be paramount. By interacting with their environment, practitioners put their knowledge into action and shape the world around them (Raelin, 2007). Practitioners committed to what is defined as critical reflection learn to observe and test their tacit processes in day-to-day situations, imbuing them with meaning through their conversational interactions with others. Managers who achieve mastery of their posts have acquired their practical wisdom by coming up against a multitude of situations. This mastery goes above and beyond what they learned in school or university (Raelin, 2007). They become capable of transcending rational explanations and finding creative solutions to the new situations they encounter. In this way, Raelin (2007) proposes an epistemology of practice founded on three core elements: tacit knowledge, critical reflection and mastery. The purpose of this epistemology is to develop learning rooted in practice (Raelin, 2006). Practice necessarily includes a tacit dimension (Polanyi, 1966), which makes it difficult to formalise. This dimension of knowledge is generally derived from an accumulation of experience (Raelin, 2007), which allows managers to build up a variety of solutions to the problems encountered in the line of duty. Critical reflection is a potentially emancipating force to the extent that it allows practitioners to examine and transform their mental models (Raelin, 2007). Indeed, the process of critical reflection leads the protagonists of a practical experience to examine the dissatisfaction, disruptions and contradictions they encounter (Reynolds, 1998; Rigg, 2018).

Raelin's (2007) epistemology of practice points to new pedagogical perspectives, allowing us to establish a dialogue between traditional business school teaching and a new approach more firmly anchored in managerial experience. That is what we now develop based on work by authors who refer to the Aristotelian concept of phronesis.

The contributions of phronesis

Current discussions on management education have been enriched by concepts derived from Aristotelian philosophy (Aristotle, 1984), specifically with reference to two of the forms of intelligence defined by Aristotle: phronesis and episteme (Antonacopoulou, 2010; Chia, 2009; Nonaka et al., 2014; Ramsey, 2014; Shotter and Tsoukas, 2014a, 2014b). The mainstream model in business schools tends to place the emphasis on episteme, adopting a scientific view of management as something which can be clearly formalised, codified and generalised. This is a model designed for the transmission of supposedly rational knowledge, based on the belief that organisational actors construct a mental representation of their actions before taking them. In this logic, action is structured with reference to predefined models (Chia, 2009) and reflection always precedes action. Knowledge is only considered pertinent if it can be transmitted through the medium of language. Learning thus consists in amassing knowledge, along with specific tools, techniques and managerial vocabulary (Sambrook and Willmott, 2014). Within this teaching model, the skills which constitute the core component of managers' practical knowledge, that is, the knowledge that allows them to get the job done on a daily basis, are absent (Chia, 2009). Given the negative consequences of an episteme-centric learning experience of this kind, it has become necessary to rebalance management education to include more contextualised and experiential forms of knowledge, encouraging young graduates to engage more fully with their day-to-day experiences.

Flyvbjerg (2001) proposed to develop Aristotelian phronesis, or practical wisdom, in the social sciences. According to Flyvbjerg (2001), the intellectual process which underpins phronesis is different from that associated with episteme. The aim of episteme is to develop knowledge that is universal and generally applicable, while phronetic action is more concerned with developing practical wisdom conducive to 
pertinent action. This interpretation of phronesis is not fully shared by scholars specialising in Aristotle (Eikeland, 2008; Laitin, 2003), who see Flyvbjerg's representation as reductive. In their view, phronesis is an intellectual quality which encompasses a broad variety of knowledge types, including episteme (Ramsey, 2014). Practical wisdom, which is largely tacit (Baumard, 1999), is the fruit of continuous behavioural adjustments in response to the flow of events. It is acquired via the banal, non-heroic experiences of situated, everyday action. In this sense, phronesis should be seen more as a virtue, that is, a form of relationship with knowledge which also incorporates practice as a process (Maclntyre, 1985).

Phronesis requires acceptance of the banal reality of the working world (Alvesson and Sveningsson, 2003), shaped more by local practices than by overarching strategic plans (Baumard, 1999). Because day-to-day management is often based on working routines, it above all involves dealing with breakdowns and unexpected events that vary in terms of significance and require solutions to be improvised in the moment (Yanow and Tsoukas, 2009). It is through such breakdowns that managers improvise solutions adapted to the situations they face. This ability to improvise is developed through both interaction and sensitivity to backtalk from the field (Yanow and Tsoukas, 2009). Aware of the emotions that they experience, and of their moral sensitivities (Shotter and Tsoukas, 2014a), enlightened managers are capable of confronting the ambiguity of professional situations and of handling the everyday realities of management. Managers' abstract knowledge does not precede their social involvement, it is a product of their day-to-day social practices (Chia, 2009; Shotter and Tsoukas, 2014b). Drawing on the epistemology of practice proposed by Raelin (2007), Ramsey (2014) put forward a scholarship of practice which relies upon attention to interactions (Nonaka et al., 2014) as its key cognitive activity, before calling upon knowledge. Ramsey's most radical idea is probably the prominence she gives to relational activities, which she considers to be the building blocks of managerial wisdom. If managerial action generally arises as a relational response to a situation, then it cannot be solely based on abstract knowledge (Shotter, 2008). Improvisation and consciousness thus become key elements in a learning process focused on practice.

As such, despite the fact that phronesis would appear to be an essential quality for managers, since it is a virtue which allows its bearers to 'attain a level of behavioural excellence and to exercise judgement' (Mercier and Deslandes, 2016: 98), it has received very little attention and recognition in the existing research on management education (Chia, 2009). Exploring this avenue of research requires the adoption of a different perspective on the world. Chia (2009) proposes

an alternative dwelling world-view whereby representational knowledge is not assumed to precede social engagement, but is deemed to emerge as a locus of understanding in the course of material social practices. Such a dwelling world-view suggests that knowledge is not some transferable, representational commodity.

(p. 25)

A managerial education based on phronesis requires some fairly radical changes. Business schools would need to develop an approach which fosters constant adaptation to local circumstances, ensuring that learning remains rooted in practical realities. The task of re-humanising management involves nurturing genuine social connections, while taking into account the diversity of management situations and the people involved. However, such a logic is difficult to put into practice, especially in an institutional context which encourages business schools to rely on epistemic teaching.

Business schools should help students to develop their capacity to 'read situations, in order to act and lead when faced with the unexpected or unknown, dealing successfully with uncertainty' (Mercier and Deslandes, 2016: 107). They must also teach them how to handle contradictions, which are inherent to the manager's job (Fiol, 2003). Practical wisdom can therefore be developed through pedagogical devices that require critical thinking and have as their starting point the kinds of breakdowns in routine that have required a response through improvisation from managers or apprentice managers. Various scholars have made proposals of this kind, often in the context of action learning, which is designed to foster learning based on experience. Pedler (2008) explains that 
Action learning is an approach to problem solving and learning in groups to bring about change in individuals, teams, organisations and systems. Through action learning people develop themselves and build the relationships that help any system to improve its existing operations and to innovate for the future. (p. 1)

It can take different forms according to whether the focus is on formulating/solving an instrumental problem, empowering individuals or, as critical management studies proposes, achieving more profound societal change (O'Neil and Marsick, 2011). Although extremely varied, the pedagogical solutions proposed are all based on the principle of reflecting on, and in, action. Those arguing in favour of a new approach to management education hold that reflection does not necessarily always precede action. Indeed, there is a reflection-in-action, which may be extended by a reflection-onaction (Schön, 1983). Nevertheless, as Antonacopoulou (2010) notes, reflection is a necessary but not a sufficient condition: one must also be allowed to engage with the tensions revealed by this process of reflection, hence the importance of nurturing the development of phronesis in students. She maintains that an approach rooted in practice offers critical advantages (Antonacopoulou, 2010), because when learners are required to use their reflexive capacities, they become aware of the tensions and contradictions in their day-to-day experience. An educational orientation based on phronesis draws upon these tensions to tease out new possibilities for action. As Antonacopoulou (2010) neatly puts it, 'a phronetic orientation and a commitment to reflexivity provide a foundation for transforming tensions into ex-tensions' (p. S7). On this basis, she proposes an interesting example of a device which permits a more integrative approach to education. Working with professionals enrolled on MBA courses, she constructed and tested a pedagogical device which integrates learners' experience. Based on interactive exercises and reading, the aim of this device is to encourage critical reflexivity by affording greater importance to learners' experiences and problems. The teacher's role is thus to support and facilitate and not to teach in the traditional sense of the word. The seminars developed by Antonacopoulou are clearly designed to interconnect theory and practice. This issue of interconnection is of central importance in the pedagogy of management, but we also think that it is essential to move beyond the theory/practice dichotomy and the applicationist view of theory.

This vision is very pregnant in professional training in general and management education in particular (Van de Ven and Johnson, 2006). As Van de Ven and Johnson (2006) claim, this is not a matter of filling a gap, but rather of capitalising on the disruptions and contradictions that inherently exist between the academic and corporate worlds.

The ability to capitalise on these disruptions is considered to be of fundamental importance within the Francophone environment, and this point is central to the work that we are conducting with students in the final year of the master's programme. Students are not experienced practitioners, but rather future managers transitioning between school and the corporate world. To design a specific pedagogical device adapted to this audience, we referred to the operational framework of FDT, which we now present.

FDT's contributions to the current debate on the pedagogy of management

Authors who share a critical vision of management education based on nurturing phronesis have put forward various solutions, broadly situated within the tradition inspired by Dewey and the enquirybased approach (Statler, 2014). If we include the contribution from Dewey, we situate our work within the tradition of French epistemology (Braunstein, 2002) and didactic theory. This framework, which we examine in this section, has allowed us to imagine a pedagogical device intended to support the development of practical wisdom among future managers. We describe this device in the last section of this article.

\section{The framework of FDT}

The aim of FDT is to study the processes of teaching and learning in terms of their specific relationship with the content being taught. This implies a dual objective: to understand the processes at play in training practices - to build knowledge about action - but also to offer recommendations designed to improve these practices and hence to build knowledge which will inform action. In this context, the 
term 'didactic' is not used in a negative sense to describe a traditional, transmissive model. The reverse is true: FDT emerged in response to the form of education centred on the teacher and affording little attention to the role of the student. Initially developed within specific disciplinary fields, FDT has historically been linked with the emergence of new knowledge and teaching practices (Sarremejane, 2001). FDT explores the teaching practices associated with identified disciplinary fields and with the theorised knowledge found in those fields. It is an operational framework that we believe could be applied to the teaching practices used in management, which today claims to possess an established body of knowledge.

FDT adopts a vision of human cognition inspired by the developmental psychology of Vygotski (1993) and Piaget (1974), in line with the epistemological tradition founded by Bachelard (1970). Vergnaud, one of the founders of FDT, builds upon Vygotski's dialectical theory of development by incorporating the notion of 'scheme' as developed by Piaget (1974). In this perspective, knowledge is built within a process of conceptualisation in action, via the 'identification of the objects which make up the world, their properties and the relations between them' and the adaptation of schemes to fit these situations (Vergnaud, 1990). We learn by forming connections between concepts that exist within a culture, validated by a scientific community and taught in an academic environment, and conceptualisations that emerge from the actions undertaken by each subject and are thus drawn from experience. This is not a matter of interconnecting different forms of knowledge (practical and theoretical). It is rather a question of implementing a dialectical process encompassing the two dimensions (operative and predicative) of knowledge. According to this tradition, knowledge is born of the dialectic between continuity and disruption and gradually emerges as networks of correspondences are constructed. The role played by epistemologies specific to individual disciplinary fields (what Bachelard calls 'regional epistemologies') is fundamental in this respect (Fabre, 2005).

Initially conceptualised with reference to specific scientific disciplines, FDT has, along with professional didactics (Pastré et al., 2006), since expanded its horizons to embrace the specificities of professional education. Among other things, it has integrated elements of Francophone ergonomics, allowing work to be seen as a facilitating environment for training. The unit of analysis for professional didactics is not the organisation; its primary objective is to conceptualise the student's development and shape the support which the educational institution provides for this process of individual construction. It thus offers a framework for constructing education situations based on the hypothesis that, although each working situation is unique and situated, they all belong to a category of situations which share certain common traits. The purpose of professional didactics is to construct paradigmatic situations that are representative of a set of professional situations, based on the analysis of activity. Teaching focuses on these situations and on the identification of their 'conceptual structure'.

Our objective is to explore the question of formal training situations encountered in business schools, focusing specifically on support for the development of phronesis. If reflective work is essential (Yanow and Tsoukas, 2009), this development requires work on the tensions that emerge during both the professional experience and the training (Antonacopoulou, 2010). According to the FDT framework, this leads to the proposal of an activity which enables students to make connections between different forms of conceptualisation. The idea is that the proposed activity should implicitly trigger a process whereby these conceptualisations are arranged into a network. The aim is to encourage each learner to take ownership of this process. In FDT, this implicit process is founded on an epistemological necessity linked to an obstacle which the student must overcome in order to construct the knowledge whose acquisition forms the object of the teaching activity (Brousseau, 1986). In this French tradition, in the wake of Bachelard's (1970) work, obstacles are necessary stepping stones to the formation of knowledge. This is a scientific enquiry, not an enquiry based on common sense, two very different things which are not always clearly distinguished in the English-speaking tradition, steeped in Deweyan pragmatism (Fabre, 2005). In order to achieve this goal, it is essential to construct problems centred on the organising concepts of effective action, incorporating both individual and collective schemes. These problems should trigger a critical process in which it is not mandatory to propose explicitly critical 
content. As we seek to define the contours of such problems, we now consider what can be learned from the concept of problematisation as defined by Fabre (2011).

Problem and problematisation

In order to facilitate the construction of skills and the interconnection of experience and academic knowledge, many authors recommend setting students with 'real' problems taken from genuine business situations (e.g. case studies) or having them work on projects. These two pedagogical forms both have their limitations, although they have acknowledged benefits. In the first case, a 'reality' is built from a situation that cannot convey all the complexities involved (Mintzberg, 2004). It transmits standards and values corresponding to the professor's vision and can therefore create disparities between students depending on their social and cultural origins. Second, within the framework of project-based pedagogy, the logic is often one of efficiency, leading to a division of the workload based on previously acquired skills: the main thing is to succeed, and it is possible to succeed without understanding (Fabre, 1999). To learn, we must transition from success, or understanding in action, to understanding, or success in thought (Piaget, 1974).

Fabre (2005) notes that Deweyan pragmatism and Bachelardian rationalism share common ground in their rejection of empiricism and the importance they place upon the construction of problems. For both philosophers, knowledge does not originate in observation. For Dewey, knowledge comes from enquiry, a natural process which is always valid whatever its subject matter. For Bachelard, knowledge finds its roots in discussion, which leads to the construction of concepts specific to certain fields of knowledge by calling former conceptions into question. Fabre proposes a form of pedagogy of problematisation which takes research as its reference practice. This approach combines elements of the thinking of both Dewey and Bachelard, marrying the enquiry-centric, success-driven logic of Dewey with the disciplinary epistemologies, focused on critical comprehension, of the French epistemological tradition (Fabre, 2011). In this tradition, 'the generic is not arrived at by applying a unique method, it is gradually and inductively obtained by establishing networks of correspondences between pockets of concepts/methods in different fields' (Fabre, 2011: 64).

In this respect, a pedagogy of problematisation requires a combination of 'subjective differentiation (my project, my problem), a clear grounding in reality (localisation) and a representative function (schematisation of reality)' (Fabre, 2011: 65). Depending on the context, this type of pedagogy may draw upon various activities. The priority is to allow students to establish and construct problems within the framework of a suitable device (Fabre, 2011). On this point, Fabre is in agreement with Mezirow (1990), who explains that constructing problems enables learners to become aware of their assumptions about the world and to engage in a process of critical reflection. In the context of FDT, learners are encouraged to become aware of 'schemes' - invariant organisations of conduct which the individual applies in action.

Fabre (1999) is very keen to stress the difference between positioning, allowing the question to emerge, and construction of the problem, formulating the terms of the question. Like Fabre, we believe that it is indeed important to differentiate between the two phases. The pedagogical device should be organised around a breakdown that students encounter in their learning experience (in the sense of Bachelard). We believe that it will enable students to identify problematic situations derived from their own personal experiences, then to construct 'template situations', the conceptual structure of which they will explore (Pastré et al., 2006) by forging connections between these situations and the theories which can cast new light upon them. In accordance with the FDT framework, the objective of the pedagogical device is to provide a form of 'scaffolding' for the reorganisation of the operational forms that learners have constructed in action, integrating the predicative forms of knowledge presented in the educational context.

The student's experience is at the heart of a pedagogy of problematisation, in the same way as for Antonacopoulou (2010). In the device that we propose, the teacher does not create paradigmatic situations based on his or her experience; situations are produced by students themselves. We believe that students will appropriate problems more readily when those problems are their own. This differs 
significantly from the problem-based learning method in which the initial problem is constructed by the professor.

Building upon the framework laid out above, we now describe the pedagogical device for management education, which we have been testing over the past few years in a European business school. Insofar as this device is based on collective critical reflection on real individual working experience, we have postulated that it should foster the development of phronesis.

A problematisation device for management

Our device is anchored in a design-based approach, which we briefly present. We explain how this device fits into our theoretical framework, a combination of CME and FDT. We then provide some background information and explain why we have chosen to work with apprentices. Finally, we describe the device, illustrating its different stages through an example of the students' production, and present the main observations made during the construction of our device.

Design-based research

For didactic theory, an educational researcher is like an engineer (this is in fact how Van de Ven and Johnson (2006) also describe the management researcher). She or he designs research, called didactical engineering, which shares some characteristics with action research, often used in management pedagogy (Van de Ven and Johnson, 2006). Yet, it differs in several respects: in didactical engineering, design is not only possible but also mandatory as this method relies on an iterative process of constructing and improving a device. The researcher is not necessarily a participant, and developing the theory is just as much of an objective as is improving the practice (Bakker and Van Eerde, 2014).

Our device is based on case studies written by students in accordance with a creative process that enables them to distance themselves from the corporate 'reality'. Indeed, it is known that writing provides a sense of perspective and fosters reflexivity (Bruner, 1996).

The first challenge is to elicit questions which will provide a source of development for learners, so that the students themselves establish the problems (Fabre, 1999). Each problem should be an obstacle, a point of breakdown in the process of knowledge construction as well as a breach of social norms. As Bruner (1996) explains, narrative formalisation is conducive to this type of questioning: 'Stories pivot on breached norms. [ ... ] That places "troubles" at the hub of narrative realities' (p. 142). Since interactions represent an essential component of the epistemology of practice (Ramsey, 2014), our device takes the form of group work. The groups are made up of people who share the same problem, derived from breakdowns they experienced in their daily actions of management (Yanow and Tsoukas, 2009). According to the FDT framework, gaining an awareness of disruptions will enable them to identify classes of problematic situations. Collective story-writing requires the co-authors to confront their different experiences, identify invariants, elaborate a template situation and identify its underlying conceptual structure (Pastré et al., 2006). However, a story can always be analysed in different ways (Bruner, 1996). Given the subjective dimension of management, this structure will depend on the students who came up with the story. Nevertheless, this structure must be based on rigorous conceptual analysis which allows participants to compare operational invariants (concepts and theorems in action) (Vergnaud, 1990), built into action by the learner, with scientific and technical concepts derived from the organisation science. In this way, they will be compelled to restructure their knowledge, and to construct new schemes of action, by confronting the formalised knowledge of the organisational sciences.

Our device comprises strictly defined steps which we set out below, after explaining a little about the students on whom it was tested. These steps are designed to engage the students in a game combining the professional and academic environments in order to launch the process whereby disciplinary knowledge is intertwined with professional experience. We believe that it should foster the development of practical wisdom among these future managers.

The choice of apprentice students 
Antonacopoulou's pedagogical device was tested on students enrolled on executive education programmes, while others have used undergraduates with little or no managerial experience (Statler, 2014). These devices are thus aimed at people who are either managers or students.

We decided to test our device on apprentice students enrolled in a master's in management. These students have a dual identity of sorts, as they are both employees of companies (generally at junior manager level) and business school students, following the same teaching programme as their full-time classmates. Rather than being a simple juxtaposition of periods, the French training system is one with precisely defined and controlled modalities: during periods spent in industry, the school follows the apprentice's professional training (and intervenes if this fails to follow the path specified), and during periods spent at school, the apprentices are paid by their companies, which are provided with regular updates about what they learned at school. Due to their dual identity, apprentices internalise the tensions between the academic world and the professional world, and these tensions become sources of knowledge (Hahn et al., 2008). Apprenticeship programmes provide a transitional space between academic education and the professional world, offering valuable development potential for individuals as well as innovation opportunities for institutions.

For several years, we have constructed training devices intended for Management Master's programme apprentices. The device that we present was first constructed in 2015. It has been adapted and then renewed every year since then in the form of a seminar organised over two consecutive days at school, towards the end of the year. Each year it involves a group of around 55 apprentice students in the final year of the Master's in Management programme. This seminar is supervised by three professors from different disciplines, including the creators of the seminar and authors of this article. These students, who alternated periods of learning and work placement in companies of different sizes and in different sectors over the course of 1 year, came from different backgrounds. Over the 3 years during which this device was tested, $54 \%$ of participants were female and $46 \%$ were male, $53 \%$ were French, $6 \%$ were European from outside France and $41 \%$ were non-European, half of whom were Chinese.

The device

The device we have developed and tested is in line with the FDT framework described above and applies the problematisation rationale outlined by Fabre (1999). It aims to encourage students to take ownership of the activity and make connections between the school activity and their professional practice, enabling them to access knowledge that has been approved by the academic community and to make it operational.

We now describe the four steps of this device and illustrate it using an example in order to better explain the process. We will then present a few general observations on the seminar itself.

The first step, positioning the problem, requires students to delineate a category of situations. It took place ahead of the seminar and consisted of asking the apprentices to each submit a significant problem that they had encountered professionally. These problems are then divided into relatively homogeneous categories by the professors in order to create the working groups for the seminar ( 9 or 10 groups). In our example, we identified a group of 6 students composed of 3 young women and 3 young men of different nationalities ( 3 French, 2 Chinese and 1 Cameroonian) who had submitted similar problems. These problems referred to the lack of access to certain folders in the company's information system, the difficulties encountered in accessing the latest version of certain data or obtaining help from other departments in gathering the information, the lack of a reliable process for selecting companies to canvas and the failure to pick up on some important information during a conference call, creating tension with the manager.

In the second step, they work together to identify the invariances which transcend the variations in the contexts and events they have shared. They then build a problem, a template situation which is representative of this category of situations. During this phase, the teachers only intervene to regulate the group dynamics if necessary. In the example described here, the invariant identified by the professors is the difficulty of sharing information within a company. This difficulty has real consequences for operational projects. In the first part of the seminar, the students identified this 
common factor by themselves and made it the starting point for their collective narrative, moving on from the positioning phase to the task of problem construction (Fabre, 1999).

The case study produced by the group, which the students entitled ' 2 million for your eyes only: Promoting the circulation of information to facilitate reporting', involves a recent graduate who finds work with a toy doll manufacturer. This young woman encounters difficulties when attempting to obtain reliable quarterly sales forecasts from the regional sales managers. The result is that she is unable to anticipate a fall in turnover, which leaves the company unable to pay the supplier who provides eyes for their dolls. A batch of dolls with no eyes is sent out to stores. The graduate is then summoned to the office of the company's financial director.

In the third step, the groups have to define a conceptual structure for the template situation they have collectively constructed. They are free to refer to different sources to develop this structure: course materials, online databases and professors. The device also leads them to refer to their peers. Each group designates a rapporteur for its team. The other members form a group of 'experts'. The rapporteur's role is to meet with three of these groups of 'experts'. She or he presents the 'experts' with the situation her or his group is facing in the form of a pitch of a few minutes. For the following 15 minutes, these experts outline their analysis of the case and make proposals for resolving the problem. We ask the groups to propose at least two different frames for the problem they constructed. We do this to help them understand the complexity of managerial situation as 'multiples frames are needed to understand complex reality' (Van de Ven and Johnson, 2006).

In their pedagogical analysis of the case, we have chosen to use as an example, the students offer two theoretical axes. They first invoke Rogers' (2003) theory of diffusion of innovation, highlighting the fact that organisational and technological innovation, in this case the information system used for sales forecasts, will not necessarily be immediately adopted by all members of an organisation. Employees may even have legitimate reasons for not adopting these innovations. It is therefore necessary to put in place organisational systems which incite staff to get to grips with the technological tools at their disposal, especially in cases where they do not see any direct personal advantage to be gained from feeding the information system. The group's second axis relies on the theory of invisible labour/hidden work formulated by Gomez (2013). In this particular case, Gomez's theory offers a critical understanding of why managers with their own, high individual performance targets might neglect the collective interest of certain aspects of their work, focusing their efforts on personal activities which can be 'objectively' assessed. These elements appear to indicate that the group combined frames of reference from several disciplines in order to understand the situation they had constructed and develop a coherent management case study based on their personal experiences.

In the fourth step, the groups share and compare their problems and analyses. During this step, they assess the professional problems constructed and analysed by three other groups of apprentices and the responses offered to these problems. Here, our group evaluated three cases of which it had no prior knowledge and was required to judge the realism of the story, the relevance of the theories employed and the operationality of the proposed solutions. Half of the final mark assigned to the group depends on their evaluations of the work done by other groups, with the other half reflecting the quality of these evaluations. The teachers give an overall score to the three assessments formed by each group: based on their own reading of the case reports written by the 3 assessed groups, they evaluate the pertinence of the assessments based on the criteria put forward (realism, relevance and operationality). At the end of the seminar, each group received all the evaluations, those made by the students from other groups and the professor's assessment of their evaluations.

Observations

The first two experiments were subjected to a detailed assessment during a debriefing session with the professors, based on notes taken throughout the experiment and on students' responses to anonymous questionnaires. This review allowed us to further refine the device and create the definitive form described above. We will now present a few elements of this review. 
We observed that the vast majority of students become strongly involved in the activity. This has been confirmed in their anonymous assessments of the seminars. Each year, $4 \%-8 \%$ of students give the seminar negative assessments, and the rest of the assessments are positive. The comments are generally very clear-cut. Students who reject the seminar explain that it would have been much more useful to spend these 2 days working at their company or doing more traditional academic activities.

After the first experiment, we decided to improve the level of scoping, since several students told us they would have liked more information beforehand ('more precise requirements, more information and details about the aim of it: what M V explained about the consultant mindset and approach').

During the first phase of the seminar, the groups are divided according to the shared problems they were confronted with, as identified by the professors based on the individual responses. The groups are not informed of the problems the professors identified and are free to choose the problem they want to focus on. We observed that the problem highlighted by a group during the seminar rarely differs from that identified by the teachers.

During this phase the students get to know each other ('good idea to get to know each other; good way to have us work together on some common problematics') and discover that they have experienced similar situations in different contexts. We observed that in a few very rare instances, students do not wish to reveal the problems they faced for various reasons. In general, when writing the story, the group uses a situation from one of its members and further develops it using other members' situations ('we started by using one of the team member's stories and we added events inspired by other team members' situations'). The story is therefore strongly rooted in their professional experiences.

During the consultation phase, we observed that the rapporteur engages in a reconstruction of the story during the consultation process and the subsequent debriefing session. At the same time, the other members of the group, who act as consultants, return to their own stories as they listen to the presentations of other groups who have come to consult with them. All the groups stress the importance of this phase of interactions with members of other groups, as it furthers progress of their work, whether in improving the clarity of the story, developing solutions or determining the relevance of theories.

The groups are required to provide supporting documents which explain their stories (teaching notes). In these notes, they must explicitly formulate the problem they have decided to explore. They must then present the theoretical frameworks they have identified before confronting these frameworks in order to come up with potential solutions to their problem. We had anticipated that the drafting phase for the teaching notes would be the most difficult aspect since it could be seen as artificial: in their comments the students explained that they were looking for tools to clarify the operational solutions they had chosen ('the theories came naturally as we were thinking of solutions'). Sometimes it was more complicated ('in the beginning we had no solutions and felt like we had reached a dead end. It was difficult to find theories'). The 'theories' that students used had different levels of abstraction: some were consultancy formulas while others were inspired by established theories. The concepts that were used most frequently were related to the structure of the organisation, corporate culture, working methods, change management, management style, workplace equity and power relationships. However, we observed that leadership and motivation concepts were rarely used, despite being essential components of traditional teaching. Regardless of the theories employed, we found the students were led to reflect on the operational capacity of the theories and therefore to critique and reject some theories.

The students put a great deal of effort into the final phase in which they assess the cases produced by three other groups. We found that we needed to increase the time devoted to this phase. During the first trial seminar, several groups told us that they would really have liked to assess these cases all together, but they had needed to divide up the work due to time constraints. We observed their strong desire to work together in assessing the other groups' work.

One important characteristic of this pedagogical device is that it encourages students to successively occupy multiple roles connected with different identities in their fields of expertise (student, junior 
manager, consultant, senior manager and director). It requires students to navigate not only amid the roles they have occupied themselves but also among the roles they have not (yet) held. During Step 1, for example, the students draw upon their personal experience as apprentices or junior managers. Then in Step 3, they must step into the shoes of a senior manager or consultant during an expert consultation process. In Step 4, they must think like members of the board of directors. By experimenting with different identities, this device helps students reflect on the purpose of their actions when they take on the identity of a manager. As one student pointed out, it was a 'very interesting concept to let students write their own case study based on personal experiences. I think it should be further developed in the future, because it forced me to think differently, more like a manager'. We believe that some students' rejection of this activity, as mentioned above, is related to the difficulty in taking on several identities and to the desire to position themselves only as a professional or only as a student.

As we had postulated when developing this device, the observations we made during the experimentation phases seem to show that the students were led to develop critical thinking based on the disruptions and contradictions they encountered. It appeared to us that they became aware of the emotional processes that they had mobilised in action, and that this key element of critical reflection (O'Neil and Marsick, 2011) provided a fulcrum for producing theorisable knowledge. This production of meaning is a form of improvisation on action that generates practical wisdom. In producing these cases, the students' first impulse was often to rely on the dominant theories studied in class. However, they quickly realised that these theories could not sufficiently explain the situations they had experienced. In most cases, they rejected these theories in favour of a more political analysis of the situation, like the one proposed by Gomez (2013) which was used by the group that authored the work we have presented. Other groups focused their experience on issues related to discrimination, socialisation, exclusion or harassment in the workplace.

\section{Conclusion}

Based on a critical reflection on business schools and their teachings, we have proposed a critical pedagogical device designed to develop the practical wisdom of management students on an apprenticeship programme. Such a device would also be suited to students who are not apprentices, if they have completed work placement programmes, which is the case in the majority of management curricula at this level.

Reynolds $(1997,1999)$ considers true critical pedagogy to be one that combines both a critical process and critical content. However, we believe that a critical pedagogical process leads students to think critically about the traditional content taught in a business school. In this regard, it is not necessary for teachers to adopt an openly critical view of the content, since critical reflection will naturally emerge through the students' interactions as they compare their experiences with the theories they have been taught.

As such, the objective of our device was not to pass on epistemic managerial knowledge, whether critical or uncritical, but rather to introduce students to a phronetic process by forming a dialectic relationship between this knowledge and the apprentice manager's experience along with the disruptive aspects involved in this experience.

Based on the operational framework of FDT, which proposes an analysis of activity in terms of forms of organisation associated with classes of situations (Vergnaud, 1990), and which grants great importance to disciplinary epistemologies (Bachelard), we have developed a problematisation device (Fabre, 2011). We have identified three axes which constitute a framework to assist teachers in developing a pedagogy of this kind. These axes do not constitute chronological stages but should instead remain interwoven throughout the duration of the device.

The first axis consists of making students aware of the breakdowns they experienced and analysing them, in order to encourage them to explore the relationship between reflection and action (Yanow and Tsoukas, 2009). According to the FDT framework, this process should be induced naturally by the device and the epistemological need that it brings about. In the case of our device, we ask students to reflect 
on these breakdowns before the seminar so that we can organise working subgroups based on similar themes. The aim is not to ask them to change and adapt to the organisational contexts in which they encountered these obstacles. Instead, the goal is to discuss these breakdowns in subgroups in order to produce a story drawing on the common factors they identified from their individual experiences. Their experiences are pooled to develop a critical reflection that contributes to creating their story. This collaborative work provides them with greater awareness of just how commonplace these breakdowns and their effects can be. This reflection involves several stages: the drafting of an initial story, the first conceptual development, receiving insights from other students on their story and then returning to revise their story.

The second axis involves creating interaction contexts that will support and encourage critical thinking. For our device, the way in which contexts evolve throughout the seminar leads students to successively take on different roles. For example, the rapporteurs must meet with groups of consultants who are responsible for critiquing the story and proposing improvements; the expert consultants must listen to the rapporteurs to offer them constructive suggestions. As management theoreticians, students must use theoretical frameworks to inform their story and as evaluators judge the quality of their colleagues' work. These different identities assumed by the students over the course of the 2-day seminar allow them to see their organisational experiences from different perspectives and create critical distance.

The last axis involves thinking through the different stages of the device in order to develop an environment conducive to a dialectic relationship between knowledge constructed in action and the established knowledge that stems from organisation sciences. Within the framework of the device that we have described, this is first done when the students build a problem derived from a set of individual situations centred on the same themes. It is next carried out when they have to search for theories based on established knowledge and provide perspective for the situation they have described in order to elicit meaning and realistic solutions. And finally, during the final assessment phase, it occurs when they must be able to distance themselves enough from the stories they evaluate to allow them to assess the relevance of their conceptual frameworks and the appropriateness of these frameworks to the stories.

In order to guarantee that the dynamic of the three axes is respected, the teachers hosting the seminar must ensure that the process is adhered to; that is, they must make sure that the students remain in the roles allotted to them at each stage and also stick to the planned time slots, as any temporal deviation could affect the success of the seminar's subsequent stages.

Based on the work students have produced, our own observations, and feedback from colleagues who later go on to teach these students, we noted that the students who participated in this seminar committed to a process of critical reflection. Of course, this critical stance is relative, given that it was only a 2-day seminar. Yet, we believe that a process has been instigated that will allow students to develop their practical wisdom and distance themselves from the managerialism they are immersed in. It is now important to further explore the manner in which the device influences the construction of this practical wisdom, by studying the impact of variations in culture, gender, and academic and professional background on how the device is understood. The next stage of our research project consists in analysing the joint development of critical reflexivity and of the conceptualisation process, based on recordings made throughout the seminar. We plan to conduct individual interviews once the students have integrated the world of work in order to ascertain whether the device has long-term effects on the practices of young managers who have benefitted from it. As emphasised by O'Neil and Marsick (2011), the challenge is to produce effects at a more societal level.

This device is intended for students participating in apprenticeships or who have completed work placements. However, we believe it would be possible to develop other pedagogical devices based on the same reasoning. It could, for example, be developed in the context of the activities of student associations, which are well developed in business schools. These activities provide practical experience for numerous students during their initial training, and this experience is almost never analysed from a critical perspective. It could also be adapted to train young teachers, who do not always benefit from 
pedagogical support, or even business mentors, who often comment at meetings organised by us that they experience difficulties in carrying out their role.

At a time when business schools are facing strong criticism, a device of this kind, based on a pedagogy of problematisation (Fabre, 2011), appears to us to be capable of fostering the development of critical reflection among future managers, not by presenting them with critical concepts and theories as yet more models disconnected from reality, but by building on their experience and on the analyses that they produce from this experience once it has been discussed among themselves. The device gives them an awareness of the importance of reflection and enables them to engage, through collective work, in a process of reorganising their operational knowledge by interfacing their individual experiences with theories provided in school.

\section{References}

Alvesson M and Sveningsson S (2003) Managers doing leadership: The extra-ordinarization of the mundane. Human Relations 56(12): 1435-1459.

Antonacopoulou E (2010) Making the business school more 'critical': Critique based on phronesis as a foundation for impact. British Journal of Management 21(Suppl. 1): S6-S25.

Aristotle (1984) Nicomachean ethics. In: Barnes J (ed.) The Complete Works of Aristotle, vols I and II. Princeton, NJ: Princeton University Press, 1729-1867.

Bachelard G (1970) La formation de l'esprit scientifique. Paris: Vrin.

Bakker A and Van Eerde HA (2014) An introduction to design-based research with an example from statistics education. In: Bikner-Asbahs A, Knipping C and Presmeg N (eds) Doing Qualitative Research:

Methodology and Methods in Mathematics Education. New York: Springer, 429-466.

Baumard Ph (1999) Tacit Knowledge in Organizations. London: SAGE.

Braunstein JP (2002) Bachelard, Canguilhem, Foucault: le « style français » en épistémologie. In: Wagner $P$ (ed.) les philosophes et la science. Paris: Gallimard, 920-963.

Brousseau G (1986) Fondements et méthodes de la didactique des mathématiques. Recherches en Didactique des Mathématiques 2(7): 33-115.

Bruner J (1996) The Culture of Education. Cambridge, MA: Harvard University Press.

Burgoyne J (1973) An action research experiment in the evaluation of a management development course. Journal of Management Studies 10(1): 8-14.

Burgoyne J and Reynolds M (1997) Management Learning. London: SAGE.

Chia $R$ (2009) The nature of knowledge and knowing in the context of management learning, education and development. In: Armstrong SJ and Fukami CV (eds) The SAGE Handbook of Management Learning, Education and Development, Education and Development. London: SAGE, 25-41.

Chia R and Holt R (2008) The nature of knowledge in business schools. Academy of Management Learning \& Education 7(4): 471-486.

Clarke T and Clegg S (2000) Management paradigms for the new millennium. International Journal of Management Reviews 2(1): 45-64.

De Geuser F and Fiol M (2003) Faire face aux situations complexes: la blessure narcissique des managers. In: Moingeon B (ed.) Peut-on former les dirigeants? - L'apport de la recherche. Paris: L'Harmattan, 99-125.

Dehler GE, Welsh A and Lewis MW (2001) Critical pedagogy in the 'new paradigm'. Management Learning 32(4): 493-511.

Easterby-Smith MPV (1986) Evaluation of Management Education, Training and Development. Aldershot: Gower Publishing.

Eikeland O (2008) The Ways of Aristotle: Aristotelian Phronesis, Aristotelian Philosophy of Dialogue, and Action Research. Oxford: Peter Lang. 
Fabre M (1999) Situations problèmes et savoir scolaire. Paris: Presses Universitaires de France.

Fabre M (2005) Deux sources de l'épistémologie des problèmes: Dewey et Bachelard. Les Sciences de I'Education - Pour l'Ere Nouvelle 38(3): 53-67.

Fabre M (2011) Eduquer pour un monde problématique: La carte et la boussole. Paris: Presses Universitaires de France.

Fiol M (2003) Les contradictions inhérentes au management - de la logique du curseur à celle de l'extenseur. In: Moingeon B (ed.) Peut-on former les dirigeants? L'apport de la recherche. Paris: L'Harmattan, 231-267.

Flyvbjerg B (2001) Making Social Science Matter. Cambridge: Cambridge University Press.

French R and Grey C (1996) Rethinking Management Education. London: SAGE.

Ghoshal S (2005) Bad management theories are destroying good management practices. Academy of Management Learning \& Education 4(1): 75-91.

Gomez PY (2013) Le travail invisible: Enquête sur une disparition. Paris: François Bourin Editeur.

Grey C (2004) Reinventing business schools: The contribution of critical management education. Academy of Management Learning 3(2): 178-186.

Grey C and Mitev N (1995) Management education: A polemic. Management Learning 26(1): 73-90.

Hahn C, Alexandre-Bailly F, Geay A, et al. (2008) Former les managers: quand l'alternance s'invite dans le débat. Paris: Vuibert.

Hawawini G (2005) The future of business schools. The Journal of Management Development 24(9): 770-782.

Kilkauer T (2011) Management and emancipation - two opposing ideas. International Journal of Social Economics 38(6): 573-580.

Knights D (2015) Binaries need to shatter for bodies to matter: Do disembodied masculinities undermine organizational ethics? Organization 22(2): 200-216.

Laitin D (2003) The perestroikan challenge to social science. Politics \& Society 31(1): 163-184.

Laufer R (1994) Mutations de la société et enseignement de la gestion: science, technique et pratique. In: HEC (ed.) L'école des managers de demain. Paris: Economica, 284-308.

MacIntyre A (1985) After Virtue. London: Duckworth.

Mercier G and Deslandes G (2016) Ethique des vertus et leadership de la phronesis à la mise en capacité. In: Brasseur M (ed.) L'éthique et l'entreprise. Paris: L'Harmattan, 97-110.

Mezirow J (1990) On critical reflection. Adult Education Quarterly 48(3): 185-198.

Mintzberg H (2004) Managers Not MBAs: A Hard Look at the Soft Practice of Managing and Management Development. San Francisco, CA: Berrett-Koehler.

Mintzberg H and Gosling J (2002) Educating managers beyond borders. Academy of Management Learning \& Education 1(1): 64-76.

Moss-Kanter R (2005) What theories do audiences want? Exploring the demand side. Academy of Management Learning \& Education 4(1): 93-95.

Nodoushani O and Nodoushani PA (1996) Rethinking the future of management education. Human Systems Management 15(3): 173-182.

Nonaka I, Chia R, Holt R, et al. (2014) Wisdom, management and organization. Management Learning 45(4): 365-376.

O'Neil J and Marsick VJ (2011) The varieties of action learning in practice: A rose by any other name? In: Pedler M (ed.) Action Learning in Practice. New York: Gower Publishing, 183-193.

Pastré P, Vergnaud G and Mayen P (2006) La didactique professionnelle. Revue Française de Pédagogie 154: 145-198.

Pedler M (2008) Action Learning for Managers. 2nd edn. New York: Gower Publishing.

Pérezts M, Faÿ E and Picard S (2015) Ethics, embodied life and esprit de corps: An ethnographic study with anti-money laundering analysts. Organization 22(2): 217-234. 
Petriglieri G and Petriglieri JL (2015) Can business schools humanize leadership? Academy of Management Learning \& Education 14(4): 625-647.

Pfeffer J (2005) Why do bad management theories persist? A comment on Ghoshal. Academy of Management Learning \& Education 4(1): 96-100.

Piaget J (1974) Réussir et comprendre. Paris: Presses Universitaires de France.

Polanyi M (1966) The Tacit Dimension. Garden City, NY: Double-day.

Raelin JA (2006) Does action learning promote collaborative leadership? Academy of Management Learning and Education 5(2): 152-168.

Raelin JA (2007) Toward an epistemology of practice. Academy of Management Learning \& Education 6(4): 495-519.

Ramsey C (2014) Management learning: A scholarship of practice centred on attention? Management Learning 45(1): 6-20.

Reynolds M (1997) Towards a critical management pedagogy. In: Burgoyne J and Reynolds M (eds) Management Learning. London: SAGE, 312-328.

Reynolds M (1998) Reflection and critical reflection in management learning. Management Learning 29(2): 183-200.

Reynolds M (1999) Grasping the nettle: Possibilities and pitfalls of a critical management pedagogy. British Journal of Management 10(2): 171-184.

Rigg C (2018) Somatic learning: Bringing the body into critical reflection. Management Learning 49(2): 150-167.

Rogers EM (2003) Diffusion of Innovations. 5th edn. New York: Free Press.

Sambrook S and Willmott $H$ (2014) The rigor of management education and the relevance of human resource development: Natural partners or uneasy bedfellows in management practice? Management Learning 45(1): 39-56.

Sarremejane P (2001) Histoire des didactiques disciplinaires. Paris: L'Harmattan.

Schön DA (1983) The Reflective Practitioner: How Professionals Think in Action. London: Temple Smith.

Shotter J (2008) Dialogism and polyphony in organizational theorizing: Action guiding anticipations and the continuous creation of novelty. Organization Studies 29(4): 501-524.

Shotter J and Tsoukas H (2014a) Performing phronesis: On the way to engaged judgment. Management Learning 45(4): 377-396.

Shotter J and Tsoukas H (2014b) In Search of phronesis: Leadership and the art of judgment. Academy of Management Learning \& Education 13(2): 224-243.

Statler M (2014) Developing wisdom in a business school? Critical reflections on pedagogical practice. Management Learning 45(4): 397-417.

Thomas AB and Anthony PD (1996) Can management education be educational? In: French R and Grey C (eds) Rethinking Management Education. London: SAGE, 54-75.

Van de Ven AH and Johnson PE (2006) Knowledge for theory and practice. Academy of Management Review 31(4): 802-821.

Vergnaud G (1990) La théorie des champs conceptuels. Recherches En Didactique Des Mathématiques 10(2-3): 133-170.

Vygotski L (1993) Pensée et langage. Paris: La Dispute.

Willmott H (1994) Management education: Provocations to a debate. Management Learning 25(1): 105136.

Yanow D and Tsoukas H (2009) What is reflection-in-action? A phenomenological account. Journal of Management Studies 46(8): 1339-1364. 